University of Nebraska - Lincoln

DigitalCommons@University of Nebraska - Lincoln

Faculty Publications from the Department of Electrical \& Computer Engineering, Department Electrical and Computer Engineering

2002

\title{
An Airborne Low-Cost SAR for Remote Sensing: Hardware Design and Development
}

\author{
Ram Narayanan \\ University of Nebraska-Lincoln \\ Paul C. Cantu \\ University of Nebraska-Lincoln \\ Xiaojian Xu \\ University of Nebraska-Lincoln
}

Follow this and additional works at: https://digitalcommons.unl.edu/electricalengineeringfacpub

Part of the Electrical and Computer Engineering Commons

\begin{abstract}
Narayanan, Ram; Cantu, Paul C.; and Xu, Xiaojian, "An Airborne Low-Cost SAR for Remote Sensing: Hardware Design and Development" (2002). Faculty Publications from the Department of Electrical and Computer Engineering. 152.

https://digitalcommons.unl.edu/electricalengineeringfacpub/152
\end{abstract}

This Article is brought to you for free and open access by the Electrical \& Computer Engineering, Department of at DigitalCommons@University of Nebraska - Lincoln. It has been accepted for inclusion in Faculty Publications from the Department of Electrical and Computer Engineering by an authorized administrator of DigitalCommons@University of Nebraska - Lincoln. 


\title{
An Airborne Low-Cost SAR for Remote Sensing: Hardware Design and Development
}

\author{
Ram Narayanan, Paul C. Cantu and Xiaojian Xu \\ Department of Electrical Engineering, University of Nebraska-Lincoln \\ 209 N. Walter Scott Engineering Center, Lincoln, NE 68588-0511, USA \\ Tel: (402)472-5826, Fax: (402)472-4732, Email: ram@doppler.unl.edu
}

\begin{abstract}
An airborne low-cost synthetic aperture radar (SAR) is under development at the University of Nebraska-Lincoln. The SAR system is an X-band, stepped-chirp frequency modulation (SCFM) radar system. One of its unique features is that the waveform generation consists of a timing-controlled D/A converter and VCO arrangement to synthesize the SCFM signal, whereby allowing for less design complexity and a much lower overall system cost. In this paper, we present a brief description of the system and some computer simulation results.
\end{abstract}

\section{INTRODUCTION}

The University of Nebraska-Lincoln (UNL) commenced the design and development of a low-cost airborne SAR in January, 2001 to support our Airborne Remote Sensing Program. The objectives of this project are to design and construct an imaging radar system using basic $\mathrm{RF} /$ microwave components for the remote sensing of underlying terrain parameters (tree height, soil moisture, biomass content, etc.) from an airborne platform of heights up to 1,500 meters. The SAR system is an X-band, stepped-chirp FM, single polarization radar system. One of its unique features is that the signal generation consists of a timing-controlled D/A converter and VCO arrangement to synthesize the step-chirp signal, whereby allowing for less design complexity and a much lower overall system cost.

The specifications of the individual block-segments including a stepped-chirp FM waveform synthesizer, transmit and receive paths, antennas, quadrature detection and image signal processing have been finalized. The microwave system of the SAR has been designed and constructed and is currently under calibration and initial field testing from a van-mounted boom.

In this paper, we present a brief description of the system design and some computer simulation results.

\section{SYSTEM DESCRIPTION}

A simplified block diagram of the SCFM SAR system is shown in Figure 1.

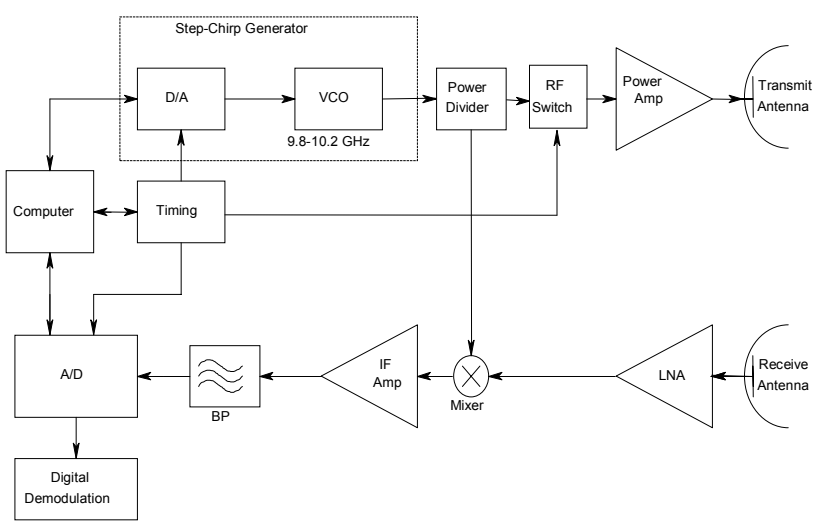

Figure 1: Simplified block diagram of the SAR system.

\section{Transmitter channel}

The frequency-stepped chirp is a discrete form of a linear FM (LFM) signal and is derived from a D/A converter controlling a VCO output. The chirp burst linearly varies in frequency starting at $9.8 \mathrm{GHz}$ to $10.2 \mathrm{GHz}$, with a pulse width of $76.8 \mu \mathrm{sec}$ and PRF of $400 \mathrm{~Hz}$ in 512 frequency steps. The synthesized signal is divided into two paths with equal power levels. One path will feed the RF switch and the other will be directed to the mixer, to serve as a reference signal.

The timing card, along with the RF switch, controls the synthesized chirp-burst gate width. During the gate width, the transmitted signal has an uninterrupted path to the RF amplifier and out to the transmitting antenna. However, any time outside the chirp burst period, the output of the power divider and the input to the power amplifier are suitably terminated. The generated signal is amplified by a $40 \mathrm{dBm}$ (10 Watts) power amplifier before being radiated out through the transmitter antenna.

\section{Receiver Channel}

The receiver is of a homodyne (stretch) design, whereas, the synthesized transmitted signal is used in place of a separate local-oscillator (LO) as a reference signal. The overall system's noise-figure is primarily determined by the receiver's front-end. Therefore, a low-noise amplifier 
(LNA) of $f_{N}=1.2 \mathrm{~dB}$ and a gain of $30 \mathrm{~dB}$ is used as the first stage of the front-end. The LNA amplifies the echo signal from the receiver antenna and is then mixed with the reference signal to produce an IF signal which retains full phase information.

The mixer is a vital component in the receiver channel, as it is the means by which the incoming RF is down converted to the IF stage. The resultant intermediate frequency (IF) signal is amplified and passed through a band pass filter (BPF). At this point, the BPF will reject all signals outside of the desired passband. The intermediate frequency of the passband is $f_{I F}=26 \mathrm{MHz}$ with bandwidth $\Delta f_{I F}=7 \mathrm{MHz}$.

\section{Antennas}

The transmit/receive antennas are microstrip plate arrays. The physical characteristics of these antennas of being small, flat and light weight will aid in their mounting onto the aircraft without significantly affecting the aircraft's aerodynamics. The antennas have a gain of $25 \mathrm{dBi}$ with a beam width of $8^{\circ} \times 12^{\circ}$. Each antenna panel is $30.5 \mathrm{~cm} \mathrm{x}$ $38.1 \mathrm{~cm}$ and the antennas are vertically polarized.

\section{System Timing}

The system timing is perhaps one of the more difficult tasks of the SAR design. Timing coordination within the design will be controlled via a NI PCI-6022 computer timing card. This task is vital for the synthesis, gating and transmission of the transmit signal, as well as providing synchronization of data acquisition and image processing.

\section{SIMULATION RESULTS}

In a low-cost SCFM waveform synthesizer based SAR system, one of the important issues in this design is how the frequency error in the frequency-stepped chirp generator caused by the non-linearity of the VCO, impacts the SAR imaging performance. Computer simulation was conducted to study this issue.

Figure 2 shows the typical point spread function (PSF) for the ideal case (where a Hamming window is applied in the processing) and for the case where there are frequency linearity errors. In this figure, the frequency linearity is assumed to be $0.2 \%$, and the frequency error is normally distributed. A total of 512 frequency steps are used. (a). Frequency vs. Time

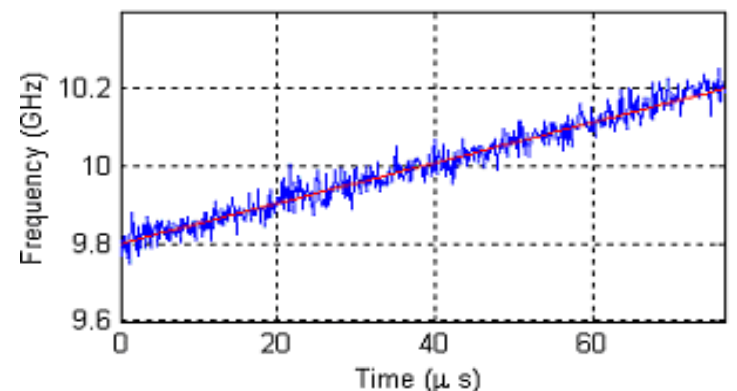

(b). Point Spread Function

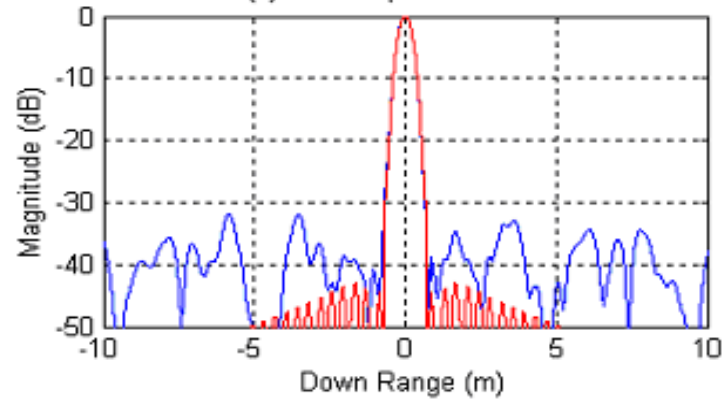

Figure 2: Frequency linearity error and the corresponding PSF sidelobes.

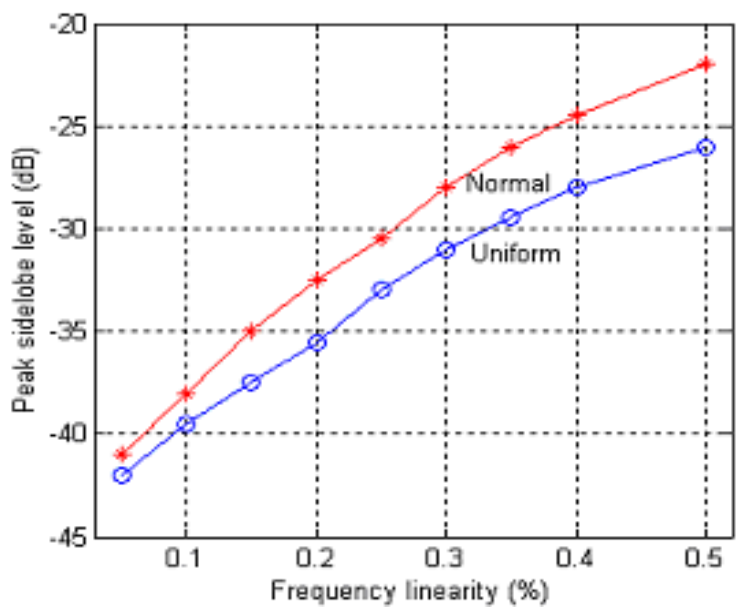

Figure 3: Peak sidelobe level as a function of the frequency linearity.

In Figure 3, the peak sidelobe level of the PSF as a function of the frequency linearity is illustrated, for both normal and uniform distribution cases of the frequency errors. It is seen that for a $30 \mathrm{~dB}$ dynamic range for the images, the frequency linearity should be better than $0.2 \%$. This can be realized by carefully choosing an appropriate pulse duration time and the PRF. 


\section{CONCLUSIONS}

The University of Nebraska is developing a unique linear FM synthetic aperture radar (SAR) system to be mounted on an airborne platform. The uniqueness lies in synthesizing the stepped-chirp frequency modulated transmit signal to reduce the effects on sweep nonlinearity. The SAR system is undergoing testing/calibration, and anticipated to be fully operational and installed on the aircraft by the $4^{\text {th }}$ quarter of 2002 .

\section{ACKNOWLEGEMENTS}

This project is supported through a grant from the NASA EPSCoR program through the Nebraska Space Grant Consortium. 